\title{
Strategic Issues of Regional Development: Government Policy Evaluation of Papua
}

\author{
Akbar Silo \\ Cenderawasih University Papua, Indonesia \\ assilo708@gmail.com
}

\begin{abstract}
The five-year period of development as outlined in the document RPJMD (Medium-Term Regional Development Plan), has achieved significant success, although there are still conscious strategic issues that are unsolved optimally. It can be traced from a series of evaluation studies to ensure consistency between the programs organized in 5 years with defined policy agenda to achieve the vision of local government. This study was conducted in a pragmatic approach that emphasizes the evaluation of policies: First, Integratif. An evaluation of the program and its financial package on cross institutions (Ind: SKPD/regional work unit). Secondly, comparatively, the achievements of development program compared with: (a) the goals stated in the document of Medium-Term Regional Development Plan (RJPMD/Ind), (b) development of mean achievement average per year, (c) the achievements of other areas, including a national scale and the achievement of the MDG's (Millennium Development Goal's).Object of the study are: All the goals set out in the mission to realize its vision of regional development as well as development programs and activities to achieve the targets and affect from various sources of financial. This study covers the gains of development programs within 5 years, including: macro achievements and outcomes for each development field. In addition, it is also obtained a description of the degree of relevancy, coherence, and correspondence between the realization of programs and activities with targeted goals, as well as the achievement of the mission and the development agenda so it can be measured the degree of the medium-term vision achievement. The district/city as a target sample of the study is Jayapura District, Puncak Jaya, District, Mimika District, and Jayapura city.
\end{abstract}

Keywords: Strategic, Regional Development, Policy Evaluation

\section{Introduction}

In the framework of the implementation of Law No. 32 of 2004 on Regional Government, has put aspects of the regional authority in a strategic position. With these laws, the region gained broad latitude to determine its own internal affairs by the authority is in accordance with the aspirations of the people. Furthermore, in order to accommodate the initiative and creativity of the region, the Government has set up a regulatory framework development planning through Act No. 25 of 2004 on National Development Planning System, which actually serves as a "major corridor" for the management of national and regional development, particularly related to the preparation plan development, implementation mechanisms and performance evaluation of development programs. On the other hand, the framework of regional development in Papua province, intercepted by the spirit and philosophy of Law No. 21 of 2001 on Special Autonomy for Papua Province. The implication, each district / city are required to synchronize the authority in order to create harmony between the two levels of authority in these regulations. On the basic of specialization, the necessary adjustments to articulate authority as "added-justification". Accordingly, the Government of Papua Province has a "special authority" within the framework of governance and development that is oriented on raising the dignity of the Papuan People heading into independence in various aspects of life. The authority is distributed to the districts / cities in the region.

In terms of evaluation of development, as outlined in the Indonesian Government Regulation No. 6 of 2008 on Regional Government Management Evaluation Guidelines, paragraph 2, is necessary to EKPPD (Performance Evaluation of Regional Government) at the End of Term of Office of Regional Head. Meanwhile, in the Minister Regulation No. 54 Year 2010 on the Implementation of Government Regulation No. 8 of 2008 on Stages, Procedure for Preparation, Control, and Evaluation of the Implementation Plan for Regional Development, in Paragraph 7, hinted that the Head of Regional Development Planning Agency / State must exercise control and evaluation of the implementation of the RPJMD (Medium Term of Regional Development Plan). Related to 
that, in order to understand the degree of success of development required the measurement and assessment of the existence of the development plan and its implementation. That measure the successful management of development is related to the articulation of the regional authority in various planning documents, for example in the form RPJPD (Long Term of Regional Development Plan), RPJMD, RENSTRA SKPD (strategic plan for sectors-working units), RENJA (annual plan), and other planning documents that are hierarchically have relevance hierarchical relationship with development plans at the national and provincial level to the level of districts and villages. Based on the authorization, the construction can be managed in a planned and sustainable oriented to the fulfillment of basic needs, improved public services, and poverty reduction. Although, in the last 5 years, the government faces a number of factors weaknesses (internal) and challenges (external) as part of the dynamic development of governance and political consciousness of society. These dynamics require the intensity of initiative and creativity in articulating regional authority optimally.

As we know that in the period of government, has prepared a 5-year development plan matured as engraved in the RPJMD document. In order to achieve the vision and mission of the construction of a 5 -year, the general strategy of achievement include: First, the regional development strategy, intended as a development approach that is tailored to the General Plan Spatial (Spatial Plan), attempted to reach the vertices new development of the region in order to avoid buildup in the central districts, through the further elaboration than the spatial plan the layout plan more specific. Second, the strategy of public welfare development, as a manifestation of the responsiveness of demand to empower people towards physically and mentally welfare society. Focus approach, making man as a central point of development, man as the subject of development is not the object of development with a core of local community empowerment. Further, it is mentioned that in general the target within 5 years implemented through strategies to achieve 5 main priorities, namely: education, health, community economy, infrastructure, and social culture.

\section{Literature Review}

As stated in the document of the Long-Term National Development Plan (RPJPN) 2005-2025, in order to realize equitable and fair development, there should be the distribution throughout the region by improving the quality of life and welfare of the community. This is consistent with the world view as expressed in its interaction in the context of MDG's, where Feeny and Clarke (2009) states that they are designed to address many of the multidimensional aspects of poverty and includes: (1) eradicating extreme income poverty and hunger, (2) achieving universal primary education; (3) promoting gender quality; (4) reducing child mortality; (5) improving maternal health; (6) combating HIV/AIDS, malaria, and other diseases; (7) ensuring environmental sustainability; and (8) developing a global partnership for development. These include efforts to reduce the development gap between urban and rural areas. The development in rural areas it's important to reduce the gap. It requires seriousness because according Dewanti (2007), the State assets in large quantities are in rural areas, and when this potential is comprehensively developed, and it will give a great contribution to economic development not only at the local level but also at the regional and even national level.

Relevant to this case, Fatem (2011) summed up the results of his research that the large influence from conducive situation results from commitment and consistent partiality, which in turn results in a sustainable village empowerment program, unlimited freedom and opportunities for the community to manage village development, increasing public interest in development, and guaranteed improvement for community businesses based on local potentials. The contribution from the strengthening of community capacity results from efforts to improve education, health, public economy, village infrastructures, and village institutions. The small contribution from community protection results from the lack of legal protection that ensures sustainable community empowerment, lack of facilitation in promotion and marketing, and lack of protection for the folk communities' rights. The major problem in the current rural development is poor accessibility and mobility between rural areas or between rural and urban ones. If this is not achieved, undoubtedly poverty continues to grow, as stated by Robinson and Thagesen (2004), that conventional poverty can be measured by the level of income or expenditure does to reach the living standards. Meanwhile, according to the World Bank, those who earn US $\$ 370$ per year or 10,000 per day were classified as poor. Thus, many available opportunities for development should be optimized by each region, through the patterns of integrated management, including proper planning, strict implementation, and evaluation are attached. In that case, an 
evaluation related to the desire to determine the success and failure of a policy, program, and activities is needed. It required a depiction of the impact of a policy. Thus, an evaluation should include several activities, namely specialization, measurement, analysis, and recommendations. Specialization, are intended to identify goals or criteria by determining the focus target which is evaluated. Measurements, is required as the criteria used to assess the success, benefits, and impacts, related to the activity of gathering information relevant to the evaluation object. Evaluation is based discipline practitioners and evaluation theory comes from practice. Meanwhile, Leviton (2003), in her article, asserts that Very important has been the emergence of more comprehensive frameworks based on collective experience, and increased reliance on findings from other fields to inform us about the processes underlying utilization. The improved clarity of frameworks is important especially for the novice evaluation practitioner. The next, evaluation theory requires extensive empirical studies that take into account all the various issues and variables that interact in any given context so that the evaluation of predictive models may provide support for all of the potential outcomes of each option. According to Shadish, in Harnar, (2014) provided a clear reason why the theory of critical evaluation: includes what was done, what drives it is done, and the nomenclature given practice framework.

In this context, the evaluation can be understood as an attempt to measure and give an objective value on achievement of results of the program that had been planned in advance and carried out systematically and objectively using the relevant evaluation method. The evaluation carried out both before a program/project which is implemented (ex-ante evaluation), when progress (on-going evaluation), and after the program/ activity completed (ex-post evaluation).Objective and systematic evaluation is done taking into account the following principles: relevance, efficiency, effectiveness, impact, and sustainability. In conducting the evaluation, developed the procedure "cluster" according the stages: (1) Identify the purpose of the program to be evaluated;(2) analyze the root of the problem;(3) describe and standardize program and activities;(4) Perform measurement of the extent of the changes;(5) Determine whether the observed changes are the result of such activities or due to other causes; and (6) utilize appropriate assessment indicators in determining the measure of input, process, output, impact and benefits of a program/activity. In this case, Bitar, Hbeichi, Al-Zou'bi \& Russon (2015) explains that, "Evaluation Cluster" is the process of assessing the progress, results and impact of programming initiatives to help use this information to plan and manage program, and educate the recipient, policy makers, and other relevant communities. Then, it is mentioned that "Evaluation Cluster" is a mechanism to collect information to use in determining the extent to which it can help people improve the quality of life. As stated in the Humanitarian Response Review (2014) cluster is a group composed of sector or thematic topic chosen, depending on the setting done by the Government. Premise is basically accountability, predictability and reliability that can be improved by identifying policies and strategies of the organization responsible for the certain fields.

Development programs and activities accompanied by its evaluation plan include important questions as the basis of determining the cluster evaluation. The evaluation is conducted to get feedback so that biases the implementation of the program/development activities can be recognized, and formulated measures accurately perfected. Results of the evaluation according to Bourgeois \& Nare (2015) shows that the evaluation instrument is used which is based on the type of recommendation that has been established to provide a response to the evaluation of programs/activities that was resulted .In order to make a judgment, the evaluation results will be grouped into very successful, not successful, quite successful, successful and very successful. Indicators are the identification and classification of indicators through the collection and processing of data to determine the performance of programs and activities. In order to assess the achievement of program/development activities that have been planned and implemented, used evaluation indicators include: input, output, results, benefits, and impacts achievement of performance that is a measure of performance to achieve measurable, tangible efficiency, effectiveness, quality, and quantity of execution programs and activities. Furthermore, the types of formulation of indicators, can actually be formed: Qualitative (using the scale: excellent, enough, less); Quantitative absolute; Percentage figure; ratio scale; Average (the average rate of a population or total events) and the Index (the benchmark figure of some variable incidence). 


\section{Methodology}

This study was conducted in four districts/cities sampled in Papua Province, namely, District: Jayapura, Mimika, Puncak Jaya District, and Jayapura City. The researcher uses a combination of qualitativequantitative method, because the necessary flexibility in understanding the data. In matters related to the planning documents and evaluation of existing does not allow to only quantitative. Mixing approach, according to Greene (2007) was used to develop and examine a set of statements to describe the transformation and potentially distinguish it from the others for more specifics understanding.In the context of the macro cannot only use a qualitative approach. To achieve the objectives of this study, the researcher applied the steps as follows: (1) Selection criteria, to establish the criteria used to assess the performance of the construction.(2) Determination of criteria, based on selection criteria, set at least one criterion that is considered appropriate. So that the evaluation does not become too complicated, just use three criteria.(3) The indicator, based on selected criteria, defined indicators for each criterion.(4) Determination of parameters, for each indicator selected parameters to be specified benchmark assessments.

\section{Results}

Strategic Issues Analysis by Type of Fields-Mandatory affairs: Based on Government Regulation No. 38 Year 2007 about Division Affairs between the Government, Provincial Governments and Regional Government of Regency/City, are implicitly expalained in Article 7, obligatory is government affairs that shall be done by the provincial government and government district/city. The whole affair shall be regarded as strategic affair that has been held well. It is not mentioned in detail according to the nomenclature, as tailored to the implementation of the basic tasks and functions carried by SKPD. For example health affairs, handled by the Department of Health and Hospital Implementation Unit, classified into land affairs and government affairs, including the district, the affairs of national unity include municipal police.

Options Fields: Affair choice as referred in Article 6 of Government Regulation No. 38 Year 2007 is a real government affairs that exist and have the potential to improve the welfare of the community in accordance with the conditions, peculiarities, and potential in the regions concerned. Consist of maritime affairs and fisheries, agriculture, forestry, energy and mineral resources, tourism, industry, commerce; and transmigration. In this affair, it is not all organized, but selected only the matters that are strategic for regional excellence. In the implementation, the adjustment of the basic tasks and functions according to the organizational structure and working procedures that applied. In which, a number of such affairs, industrial affairs and trade affairs to be part of the affairs of the Department of Industry, Trade and Cooperatives and SMEs. Likewise with integrated transmigration affairs with the employment affairs. Achievement consistent implementation of programs and activities for 5 years is $47.85 \%$, in the category "Self-sufficient" with a value of 3 which implies that it is generally quite successful in conducting the affairs of choice.

According Issue Analysis Strategic Priorities for Development-Education Field: Human resource development efforts, referring to priority education sector in line with the national education development agenda as well as at the level of the province of Papua. Prioritizing education policy is meant to sharpen the direction of development objectives in order to increase competitiveness. The existence of financial support through the organization of co-administration of the Central Government and the Provincial Government of Papua, which has become a strategic opportunities that can be optimized. But not only rely on leader government support, but applied some breakthrough appropriate policies and strategies. Furthermore, the basis for the strategy was developed: First, seeking the expansion and equitable distribution of educational opportunities, especially for children aged 7-15 years. Secondly, pioneering educational boarding patterned with one-stop system; and Third, the implementation of inclusive education; Forth, regeneration children of Papua through the partnership program at internal and abroad.

Basically, it has been responded equally between the authority of a special autonomy and the charge of the Law on National Education System (adopted parallel with RPJMD). At the same time consider the achievement of the Millennium Development Goals (MDG's) in the field of education, in 2015 ensured all children aged 15 years (men and women, children, minorities and children who are less fortunate) can complete the quality of basic education. Therefore, education development foundation, carrying the paradigm 
of national education (collaborative learning), which provide more open space for stakeholders in the education sector to be actively involved in the whole process of provision of educational services. This also underlies the development of education that is able to create equilibrium-based two-dimensional, where education shall be integrated through the development of curriculum charged national and institutional, which adopt and accommodate national values and also give recognition to the existence of values that live and thrive in a society with the character of locality.

Furthermore, by using the general indicators results as the basis of assessment within a period of 5 years later, the general performance of the development achievements in the education sector was the degree of success beyond the target RPJMD with an average of $105.53 \%$ achievement. This figure was obtained through a comparison between targets and achievements RPJMD last year only in four types of indicators of outcome, i.e., the net enrollment ratio, gross enrollment ratios, and the level of literacy. As for the indicators, such as, access learning for students Papua native, ratio of participation (enrollment ratio) in Primary Education, proportion of students start in grade 1 and reach Grade 5, analyzed qualitatively with the criteria of achievements at the level of "Enough". However, it needs a carefull that should be guard against the formation of annual performance. This is in line with the aggregate results of the analysis of the consistency of program achievements and activities. With consistency in the three years beginning in the category "Self-sufficient", and in the last 2 years in the category of "Insufficient, showed a tendency to move down. It implies that, first, the education budget has been affected above the minimum of $20 \%$ of regional budget per year, does not provide adequate contribution to the implementation of programs and educational activities that are substantive. Secondly, there is still a lack of creativity in the realization of the programs and activities of substantive, which implicitly intersect with aspects of human resource development. Thirdly, the proportion of the activities of a mere administrative (non-substantive) should be limited, so that the available budget can be optimized to improve the quantity and quality of the implementation of programs and activities that are substantive in education.

Health Fields: The data base of health is needed to support one of the main strategies of human resource development in the health sector, namely improving surveillance, monitoring and health information with one of its products is the functioning of health information systems are based on data from district level down to district and village. The basic health data needed, covers all health indicators principal about the case of health (mortality, morbidity, and the number of disability), environmental health (physical environment, biological, and social), health behaviors (hygienic behavior and lifestyle), and the various aspects of health care (access, quality of care, health financing). Health Department, has been working to meet the needs of data/information with a view to mapping the objective conditions of development progress in the health sector in this area.

With anallocation budget at least $15 \%$ of the budget that has been able to be realized, then the planning and implementation of programs and health development activities must be supported by the availability of accurate and complete data. In this case, the Health Department has been trying to meet the needs of planning data as shown in RPJMD document, although not exhaustive appropriate indicators of achievement set out in the SPM Health and MDG's. Similarly, in terms of reporting development achievements in the health sector has not fully used the indicator in question. With such a composition, it can beknowthat the degree of success of health development has exceeded its target of $4.75 \%$.The figure was derived from the average of the achievements of the 34 types of indicators were identified quantitatively. While qualitatively still many aspects that need to be addressed more seriously in the future, such as, with regard to the provision of infrastructure and health facilities and the quality is adequate, inpatient services, the handling of patients with acute diseases and infectious, handling labor and birth, repairs nutrition, environmental health, as well as decreased levels of utilization of traditional medicine/herbal health standards which do not suit.

Economics Fields: Economics is one of the important priorities within the framework of development in line with national economic development policies and policies of special autonomy in Papua. In this case has a lot of programs and activities implemented by relevant agencies, and even involve the agency up to the district and village level which is well organized in the context of obligatory functions and affairs of choice, and even some of the programs and activities of which are launched from the Central Government and the Provincial Government of Papua in the form of assignment with deconcentration based. An important note in this 
regard, especially in the context of measuring the achievement of economic development, because it is faced with the conditions in which: First, the document RPJMD, is not equipped with an indicator precise measurements as the basis of assessment, but only the technical nature of operating more deserves as indicators of achievement in Strategic Planning documents or working plan. Second, integration of programs and activities of the government superiors have not been integrated into the scale of assessment of indicators of success are accurate and complete. Third, it is not enough support for data on the achievements of successful economic development per year which is ongoing and dynamic. Fourth, the various programs and activities that overlap in the form of redundant and even pitch so that potentially harm reduction in the assessment of achievements achievement, because not smooth mechanism CISS (coordination, integration, synchronization, and Simplification) across agencies related SKPD (sectors-working units). Surely nothing can be done to give consideration and evaluation, except by giving qualitative weight which is not too promising adequate degree of accuracy. However it should be noted that the agricultural sub-sector, at least marked the government's efforts to increase the intensity of land use is becoming increasingly better sleep. Likewise with livestock production continues to be driven, as well as their efforts to protect farmers against middlemen. However, food production is still considered lacking due to insufficient local needs, both grains and tubers and local food production such as sago. Therefore, the availability of food in each region is still inadequate because productivity is still low.

Meanwhile, the plantation sub-sector, as represented targeted in the year of 2011 is $690 \mathrm{~kg} / \mathrm{ha}$, it is still insufficient achievements, including a new Cocoa productivity reached 0.93 , while the production of forest and agro also still less optimal. In fisheries sub-sector, utilization marine resources, and the degree of protection of the fishermen of the middleman has strived to the maximum so that the production of fisheries and marine considered quite inadequate to meet the protein requirements of fish for the community. But aquaculture production which was originally targeted as much as 286.788 tons per hectare is still considered less equal.In Cooperatives and SME sector, the role of cooperatives as the pillar of the people's economy is still less serve to grow the creative economy to the villages and districts. It is characterized by the limited number and quality of cooperatives and SMEs or joint ventures that operate effectively with a number of members are recorded only 5.033 people still considered to have a low degree of representation. Likewise with the industry growth rate of the people who rely on the agricultural sector, especially high-value commodity adds.

In the commercial sector, still needed the availability of people who are traditional markets in the districts and villages which can operate on a regular basis every day. It does not also obtain adequate support from employer's cooperation in utilizing social responsibility to foster a creative economy in the field of trading and industry. Therefore, the aggregate economic conditions of the people who tend to move towards the negative, it can be understood if the reception area of revenue is still very limited, because the extension of regional income sources cannot be explored optimally. Furthermore, although there is a movement to improve the unemployment rate, it does not mean that it has achieved satisfactory results in terms of employment, because of the absorption of labor in the formal sector and non-formal are not encouraging. The only causal factor for the success of suppressing the number of unemployed is the job mobility of the population as a consequence of the increasing number of government funds affected to manage various programs and activities to the villages.

Infrastructure Fields: One area of strategic development priorities is infrastructure. Infrastructure development even becomes part of the policy and strategy of the Central Government and the government of the province of Papua in order to open the isolation area. Accessibilityof public services increasingly have a wider range, and further encourage the growth of the regional economy and society as well as increase social mobility. Therefore, basic infrastructure such as roads and bridges, housing, clean water, and electricity became the main inspiration in principle the increasing dynamics of community life in its various aspects. Realizing this, through SKPD institution, continues to spur the programs and activities of the construction of roads and bridges, housing, and the provision of worth clean drink water. There are 6 types of indicators that can be measured quantitatively, namely with regard to the increased length of $64.12 \mathrm{~km}$ road as far as the still far below the target RPJMD along 1,452 km to $893.94 \mathrm{~km}$ road length quality that goes far beyond the target RPJMD along $243 \mathrm{~km}$. The roads and bridges are maintained as far as $135.37 \mathrm{~km}$ while the target RPJMD is $446 \mathrm{~km}$. While the Type 36 permanent house built for the community as much as 430 units more than the 
target RPJMD only 300 units, as well as clean water network installed throughout the $18,000 \mathrm{~m}$ which is still very far from the target RPJMD along the $26,500 \mathrm{~m}$. Thus, the aggregate of the six types of activities the achievement degree of success obtained by $124.98 \%$ or generally exceeded targets ideally. The 8 types of activities for the public works and 5 types of activities for the identified transportation can only be analyzed qualitatively, in which all activities intended to obtain sufficient assessment good. However, it still needs to watch the performance of its programs and activities in the coming years, give the degree of consistency in general to 5 years later tendency toward negative.

Social and Culture Fields: Social and cultural sectors, a development that is not classifiable into areas covered in the previous development. In this case, religion, women's empowerment, family planning, culture, youth, sports, and social welfare are involved.Similar with other areas of development, socio-cultural field did not has a representative indicator for the evaluation base and does not have data sufficient achievement indicators. Thus the socio-cultural field cannot be assessed quantitatively. The qualitative assessment conducted based on public point of view which is summarized through in-depth interviews of informants. In order to empower women there are four indicators chosen, namely: The ratio of girls to boys in the level of education of primary and secondary, Share female workers of non-agricultural sectors, percentage of violence against women, the proportion of women in the scope of the bureaucracy and politics, have an assessment with negative image, in which the ratio of females to males in primary and secondary education levels regarded as still small. In general, judging that the boy still more in every level of education. The involvement of women in the agricultural sector is still limited. The violence against women is still considered common in high frequency, mostly undetected. Likewise with the participation of women in politics and government are still fewer than men. There are 900 poor married couples who are targeted as the target family planning services of family welfare programs, but their achievements assessed to be less touched on aspects of regional and fostering consistency. The number of family planning participants, which fostered 23.708 people assessed to be less than the number of families. In terms of culture, related to the promotion aspect is considered still very limited, so that the culture of various tribes are still less known in the outside world, while fostering and preservation of local culture is considered to have a promising hope for existence. Related to the youth, achievements aspect in various fields is generally assessed to be less prominent, although it is recognize spatially in the fields of politics, law, government and sports, some of whom have been able to show a proud achievement. Similarly, the productivity of the youth in entrepreneurship independently not seems significantly influence in motivating themselves and society. While in the field of sport, still magnified ask the achievements of the students, not unheard of achievement of student achievement in a sporting event at the regional and national levels. On the other hand, the participation of athletes in various events up to a mash national level need to be upgraded so that the achievements earned can reach championship title. Meanwhile, for social welfare, there is a judgment that the growing social problem, including the use of alcohol and drugs. But, it is not accompanied by efforts to prevent it maximally.

Web Design Analysis: In this section, analysis of web design using data source from the Ministry of Village, Development of Disadvantaged Regions, and Transmigration.

\section{Table 1: Baseline of 27 Mean Progress indicators and Trend Direction Standardization}

\begin{tabular}{lllll}
\hline No. & \multirow{2}{*}{ Indicator } & $\begin{array}{l}\text { Basic } \\
\text { Data }\end{array}$ & $\begin{array}{l}\text { Standardization } \\
\text { Trend }\end{array}$ & $\begin{array}{l}\text { Intervention } \\
\text { Status }\end{array}$ \\
\hline 1 & Poor family (\%) & 18.64 & $(0: 01)$ & $(*)$ \\
2 & Consumption Expenditure Per Capita (IDR) & 622.12 & $(0: 01)$ & $(*)$ \\
3 & Life expectancy (Index) & 67.32 & $0: 18$ & $(*)$ \\
4 & Average Length of School & $9: 54$ & $0: 08$ & $(*)$ \\
5 & Literacy Rate & 96.65 & $(0: 27)$ & $(*)$ \\
6 & The village which has Asphalt / Concrete road & 79 & 1.85 & $\left({ }^{* *}\right)$ \\
7 & The village which has hardened road & 27 & $0: 50$ & $\left({ }^{* *}\right)$ \\
8 & The village which has soil road & 20 & $(0.46)$ & $(* * *)$ \\
9 & The village which has other status road & 1 & $(0: 13)$ & $\left({ }^{* *}\right)$ \\
10 & Household Electricity Users (\%) & 86.85 & $0: 09$ & $(*)$ \\
\hline
\end{tabular}




\begin{tabular}{|c|c|c|c|c|}
\hline 11 & Household Phone Users (\%) & 7.70 & $0: 18$ & $(*)$ \\
\hline 12 & Household Water Users (\%) & 46.81 & $0: 21$ & $(*)$ \\
\hline 13 & The village which has non-permanent markets & 113 & $1: 05$ & $(* * *)$ \\
\hline 14 & Number of Health Facilities Per 1000 populations & 0.95 & $(0: 09)$ & $(*)$ \\
\hline 15 & Number of Doctors Per 1000 populations & $0: 32$ & $(0.37)$ & $(* *)$ \\
\hline 16 & $\begin{array}{l}\text { Number of elementary/junior high school Per } 1000 \\
\text { populations (unit) }\end{array}$ & $1: 36$ & $(0: 01)$ & $(* *)$ \\
\hline 17 & Fiscal Gap (IDR) & 195.541 & 0.86 & $(* * *)$ \\
\hline 18 & Distance average from Village to District Office (Km) & 106.59 & $0: 29$ & $(*)$ \\
\hline 19 & Access to health services $>5 \mathrm{Km}$ (Total Villages) & 18 & $(0: 14)$ & $(* *)$ \\
\hline 20 & Access to Primary Education Service (Km) & $12: 08$ & 0.86 & $(* * *)$ \\
\hline 21 & Villages Earthquakes (\%) & 2.78 & $0: 26$ & $(*)$ \\
\hline 22 & Village Landslide (\%) & $3: 47$ & $0: 48$ & $(* * *)$ \\
\hline 23 & Flood village (\%) & 11.81 & $(0: 16)$ & $(* * *)$ \\
\hline 24 & Village Other Disasters (\%) & 11.81 & $(0.49)$ & $(*)$ \\
\hline 25 & Village on Protected Areas (\%) & 42.36 & $(0.50)$ & $(*)$ \\
\hline 26 & Critical land in village (\%) & $2: 08$ & $(0: 32)$ & $(* * *)$ \\
\hline \multirow[t]{2}{*}{27} & Conflict village Rata2 1 last year (\%) & 16.67 & $(0: 17)$ & $(*)$ \\
\hline & Total Value Index & & $(0.43)$ & \\
\hline
\end{tabular}

Source: KPDT $2011\left(^{*}\right)$ less necessary; $\left(^{* *}\right)$ need; $\left({ }^{* *}\right)$ it is necessary

From a total of 27 indicators used in the assessment, there are 11 indicators that still require policy interventions, namely: access to basic education, access to health care, fiscal gap, the number of elementary/junior high school per 1000 population, number of doctors per 1000 population, the number of infrastructures Health per 1000 population. Number of villages which do not have a permanent market, the number of villages that have a dirt road, paved, and asphalt, as well as the percentage of landslide-prone villages. Based on Table 1 can be explained that when seen by the indicator turns out there are 10 indicators were "very necessary" intervention and 3 indicators with the category of "necessary" intervention. As shown in Figure 2 below followed by explanations.

Intervention Policy-Fiscal Gap: That is the amount of funds available for use in construction after deducting expenditures. Fiscal gap represents the difference between the fiscal needs and less fiscal capacity. Fiscal gap illustrates the availability of funds to finance services and public administration in the area. These indicators are commonly used to calculate the General Allocation Fund (DAU). The greater the fiscal gap indicates sufficient fiscal capacity to fund public services and governance. The fiscal gap is the value of 195.541 million, still below the average number of districts in Indonesia, namely 201.635 million. This is due to the low achievement of realization of the Regional Original Revenue. Therefore, the government is necessary (***) to intervene in order to enhance the region's fiscal ability to reduce levels of local financial dependence to the Central Government or the Provincial Government of Papua through the intensification and extension of receipt of revenue. 
Figure 1: Diagram Analysis Web Design

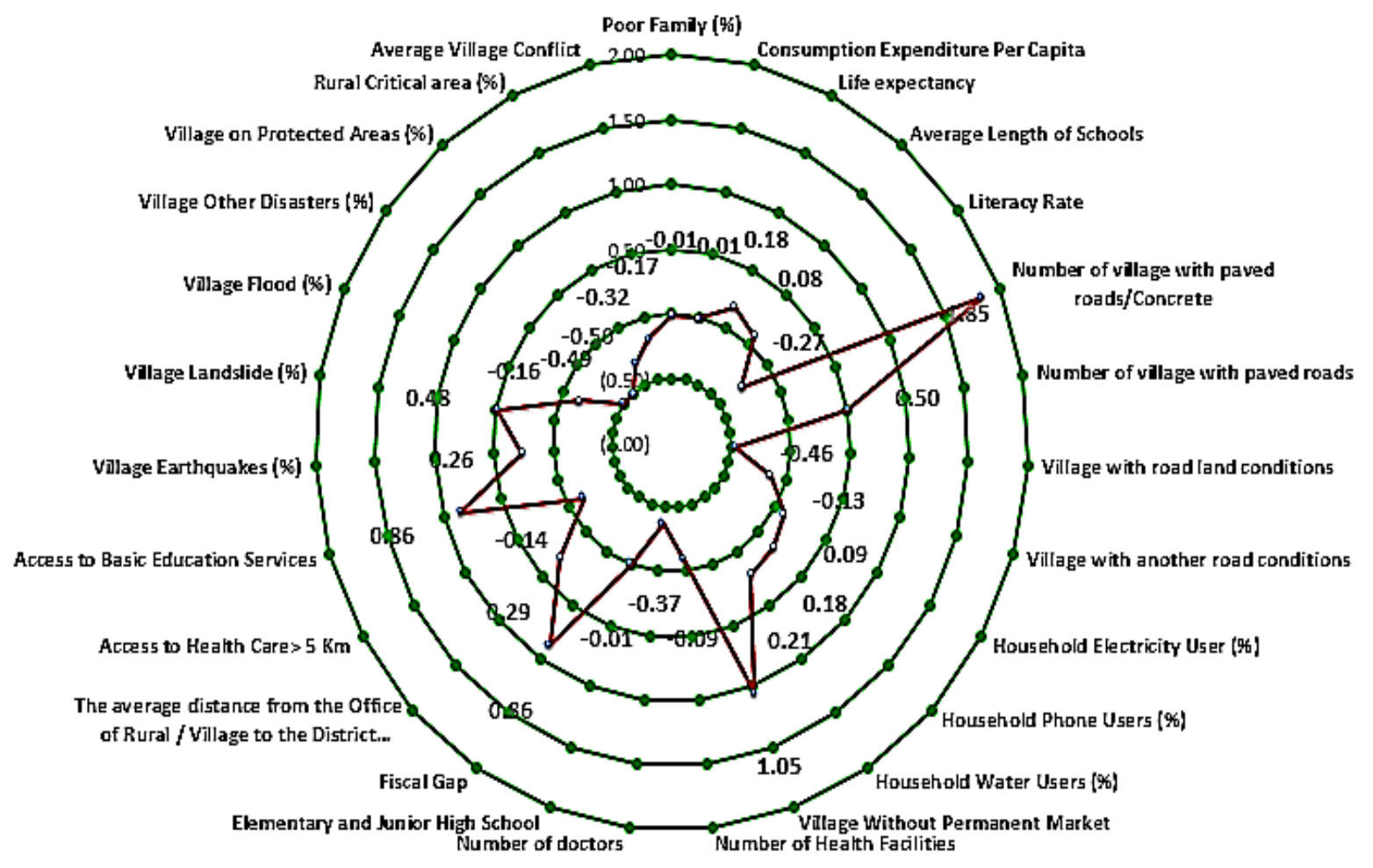

Access to Primary Education Services: On average the range of access to centers of education services as far as $12.08 \mathrm{~km}$. Apparently, these figures are above the average number of districts in Indonesia is $8.5 \mathrm{~km}$. This shows that in general, accessibility geographically is high which shows that in general, primary and secondary school students have to travel long distances from the residence to the school. Handling this issue through policy intervention is necessary $\left({ }^{* * *}\right)$ to get closer to the centers of educational services to the public more precise, among others, the school opened a patterned roof dorm. Total Elementary /Junior school Per 1000 Population is sufficient that one, 36 per 1000 population. This figure is almost equivalent to the average of districts in Indonesia that is 1.39 per 1000 population. Nonetheless, it is still necessary (**) intervention policies through various breakthroughs to increase this ratio as an alternative to the policy of the roof patterned boarding school.

Figure 2: Development Indicators Before intervention

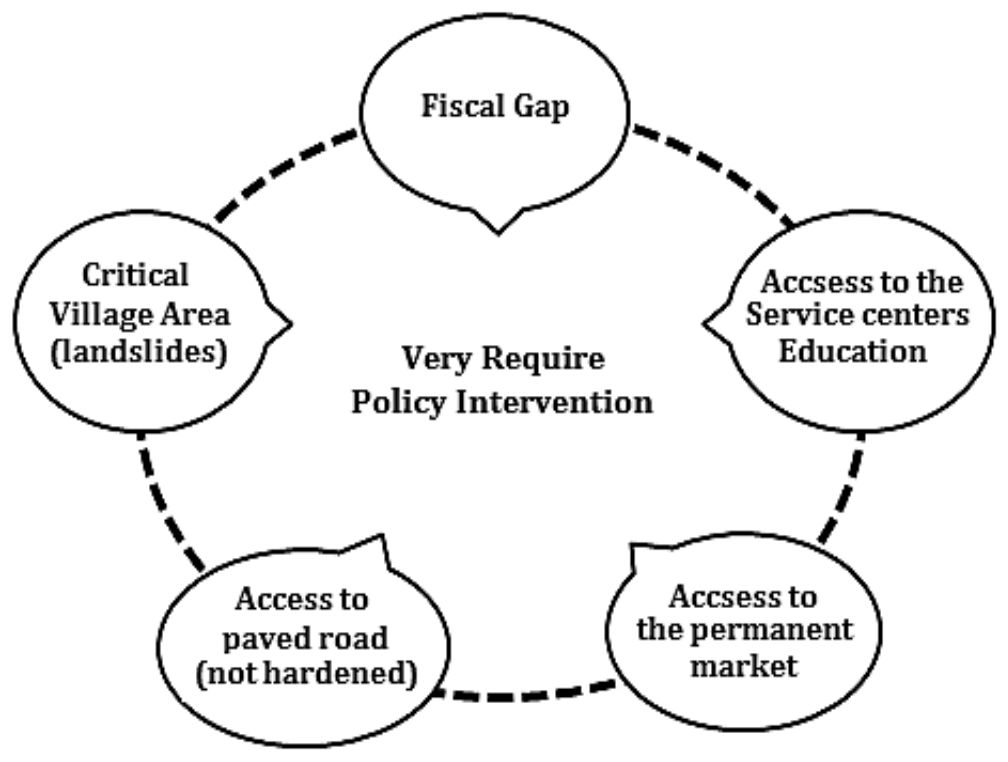


Access Health Services: There are still some villages that have access to health services within more than 5 $\mathrm{km}$ or more. Compared to the average of districts in Indonesia, this figure is still quite good. Nevertheless, it is still required ${ }^{* *}$ ) policy interventions more intense, in line with the vision of increased outreach education services cost and quality of human resources in order to build a healthy spiritual and physical. The number of doctors is sufficient, with a higher ratio than the average district in Indonesia. However, assessed still require $\left({ }^{* *}\right)$ further policy intervention in order to increase the number and quality of doctors, associated with efforts to improve the quality and coverage of health services. Where, in each unit of health services to the health center, health center Roving, and IHC qualified doctors available. Number of health infrastructure, fairly adequate, although only slightly above the average of districts in Indonesia. Although still require policy interventions are in the category of less need $(* *)$. Therefore, the dynamics of society demand continues to grow due to the increase of health care more accessible. As we know that in addition to hospitals, has been supported by the availability of adequate health centers scattered in districts and villages.

Market Village: There are still many villages that do not have a permanent market, so it is still very necessary $\left(^{* * *}\right)$ intervened. In order to spur economic growth and development of village entrepreneurship among the people of the village, is indispensable traditional market infrastructure availability permanent as one strategy to intensify the motivation of people in the business, at the same time making it as a container for the product market expansion villagers. If necessary regulated through binding regulations that at certain times of the apparatus and urban communities are required to shop at these villages.

Have Road Village and so on: Based on this indicator, Villages that have dirt roads, paved and unpaved, as many as 79 villages, is still below the district average in Indonesia that still need to be intervened $\left(^{* *}\right)$. Meanwhile, Number of villages with paved roads is still limited. Paved road is usually found on the road that connects the village with the local agricultural / plantation society. The street is very necessary ( ${ }^{* * *}$ ) improved livelihoods since most of the population is obtained from the farm. With the means of transport that connects the village with the area of agriculture or plantation, of course, can further increase the frequency and distribution of agricultural production flow channel. This too is in need (***) policy interventions in improving the status of a road paved, asphalted / concreted. Likewise with the landslideprone villages there is still approximately 3:47\%, below the national. Of course required $(* *)$ government intervention, so as to prevent landslides. In addition, necessary to reduce illegal logging in the forest. Moreover, there are still approximately 2:08\% villages have critical land, $11.81 \%$ is prone to flooding.

\section{Conclusion}

RPJMD document, not yet fully used as a reference for planning program and an annual activity by all SKPD. The general policy direction and financial policy areas, have not been consistently used as the basis for policy development in various fields and sectors, so it can't be known for certain target achievement overall. Less expensive policy implementation factors opportunities and challenges in a mature and accurate, so it does not need to happen crisis, requiring a readjustment plan and financing programs that require rationalization of local revenue sources. The formulation of the goals listed in the RPJMD document, did not explain clearly quantitative measures as well as the formulation of indicators and parameters of the size of the program and activities do not have the eligibility to serve as a reference for evaluation assessment. Indicators are formulated in accordance with the formulation of the indicators adopted by the national or at the level of the Province of Papua, and also formulated local indicators corresponding real needs of society. The Agencies of SKPD, inconsistent in implementing development programs that should be run properly every year. Many programs / activities undertaken without being based on medium-term planning document that has been agreed upon, but appeared suddenly as needed and or situational interests. There are very few programs are adequately implemented in order to achieve 5 missions and 14 goals. Most accomplished with inadequate results. Meanwhile, there are many programs and activities listed in the RPJMD document that failed to materialize, and even many programs and activities are held without an agreed reference for planning.

According to Priority Sector. during the initial three years, the priority development of education in the category "Self-sufficient", and in the last 2 years in the category of "Insufficient (on the Likert scale), show a tendency to move down. Furthermore, in the aggregate, achievement of consistent implementation of development programs in health sector, it can't be said to be the maximum, because in 5 years later 
achievements of consistency at the level of "Self-sufficient". In the economic field, there is a tendency of decreasing achievement of consistency with the achievements of aggregate for 5 years is 2.82 or categorized as "Self-sufficient". Meanwhile, in the field of infrastructure, tend toward the negative, with an average category at level 3, namely, "adequate". The aggregate outcomes consistent implementation of government programs was negative with patterned zigzag conjuncture. Meanwhile, against the development program in socio-cultural field, the aggregate gain category "Quite adequate", with the trend moving in the negative direction. This caused a decrease in the degree of consistency of program achievement. With tolerances that the average achievements per year in the category "Self-sufficient". Lead to the creation of conditions of security and order are increasingly inadequate. It is conditioned by progress pa da period of 3 years, indicated by: (1) Access to education at the level of primary and secondary education, have acquired the portion of high attention, and has a tendency to development better than at the provincial level and national , so that the degree of quality and scope of educational services is increasing. (2) The degree of health services cheaper and more quality perceived by the public (including the poor). (3) Increasing basic services for the population, especially in terms of accessibility of households to clean water and electric lighting, as well as the area of telecommunications to the districts and villages. (4) success in empowering the community for 5 last years communities that have been able to deliver a better level of welfare and into the area of best practices for other regions in Papua and outside Papua. (5) It has a great potential as a new area industrial region, and trade center primary business center in the area of Papua and West Papua, and even in the Pacific Region, as supported by the ease of investing and the security situation more conducive and accessibility land transport, water and the sea is getting better.

The other hand there are still some things that assessed yet been optimal, with respect to, (1) A large number of school-age children in primary and secondary education are not handled optimally as a direct implication of inadequate quality and affordability of infrastructure and educational facilities. (2) The availability of doctors and hospital facilities and health centers are inadequate quantity and quality according to the standards assigned, including surgical facility. (3) The assertion status of the right to land and land administration arrangements in each village / town and district, are still inadequate. Therefore, measures need to be more serious in asserting boundaries of customary rights of indigenous peoples. (4) The intensity of the development of regional culture on any existing tribe ongoing basis. (5) The success still requires follow-up financial governance improvement and development of villages optimally, should intervene administration and institutional policies on an ongoing basis. (6) The data subject is accurate and viable development is not yet available in a comprehensive, integrated, dynamic, and applicable, to be used by all sides as a common reference in policy formulation and development planning. (7) Fiscal gap is still wide in which the budget is still very high dependence. The reception itself is still very limited with a small contribution to the regional economy. (9) There may be controlled throughout the critical areas because of the low awareness of the public, although there are enhance percentage of degraded land under control. Meanwhile, the monitoring has not been significantly intensified against residents who violate the orderly build in the forbidden zone.

\section{References}

Bitar, K., Hbeichi, R., Al-Zou'bi, L. \& Russon, C. (2015). Evaluation Capacity Development through Cluster Evaluation. Journal of Multi Disciplinary Evaluation, Claremont Graduate University, 11(24). ISSN 1556-8180

Bourgeois, I. \& Naré, C. (2015). The Usability of Evaluation Reports: A Precursor to Evaluation Use in Government Organizations. Journal of Multi Disciplinary Evaluation, Claremont Graduate University, 11(25). ISSN 1556-8180.

Dewanti. (2007). The Impact of Travel Pattern on Rural Transport Development. Journal Forum Teknik Sipil, XVII/3. Yogyakarta. UGM.

Fatem, A. (2011). Policies in Village Development: Learning from Community Empowerment and Participation in Jayapura. International Journal of Administrative Science \& Organization, 18(2), ISSN $0854-3844$.

Feeny, S. \& Clarke, M. (2009). The Millennium Development Goals in the Asia-Pacific: An Introduction. Palgrave-MacMillan: London. 
Government of India Planning Commission. Ministry of Rural Development. (2006). Working Group on Rural Roads in the 11th Five Year Plan

Harnar, M. A. (2014). Developing Criteria to Identify Transformative Participatory Evaluators. Journal of Multidisciplinary Evaluation. Claremont Graduate University, 10(22). ISSN 1556-8180

Leviton, L. C. (2003). Evaluation Use: Advances, Challenges and Applications. American Journal of Evaluation, 24(4), 525-535.

Robinson, R. \& Thagesen, B. (2014). Ed. Road engineering for development. London: Spon Press

The Law on Special Autonomy for Papua, No. 21 of 2001, Supplement to the State Gazette 2001 No. 135.

The Law on National Development Planning System, No. 25 of 2004, Supplement to the State Gazette of 2004 No. 104.

The Law On Government Regional, No. 32 of 2004, Supplement to State Gazette 2004 No. 125. 